\title{
Long-Standing Goiter Causing Acute Airway Compromise
}

\author{
Debbie C. Chen, BA, Donna M. Williams, MD, and Paul B. Aronowitz, MD \\ Department of Internal Medicine, University of California, Davis, School of Medicine, Sacramento, CA, USA.
}

KEY WORDS: clinical images; endocrinology; surgery.

J Gen Intern Med 31(12): 1539-40

DOI: $10.1007 /$ s11606-016-3732-0

(c) Society of General Internal Medicine 2016

A n 81-year-old Filipino woman with a 20 -year history of benign goiter presented to the emergency department with acute shortness of breath and cough. Physical examination revealed an oxygen saturation of $76 \%$ on room air, large anterior neck mass extending most prominently to the left side of her neck, and stridor. After treatment with albuterol, steroids, and continuous positive airway pressure ventilation, symptoms were alleviated and oxygen saturation improved to $98 \%$ on room air. She was subsequently evaluated for thyroidectomy. Prior to surgery, radiograph (Fig. 1a) and computed tomography (Fig. 1b) of the chest showed massive substernal thyroid and prominent rightward deviation and severe narrowing of the trachea. After left hemithyroidectomy, chest radiograph revealed significant improvement in tracheal stenosis (Fig. 2). While onethird of patients with goiter have evidence of upper airway obstruction on flow-volume loops, ${ }^{1}$ tolerance can develop to long-standing goiters, and patients may remain asymptomatic while compensating for up to $70 \%$ tracheal compression. ${ }^{2,}{ }^{3}$ However, patients with goiter, particularly with substernal extension, may experience acute airway compromise in the setting of upper respiratory infections. ${ }^{1,4}$ Surgical management is recommended for goiters causing compressive symptoms and should be considered in asymptomatic patients with substernal goiter and objective evidence of upper airway obstruction. 5,6
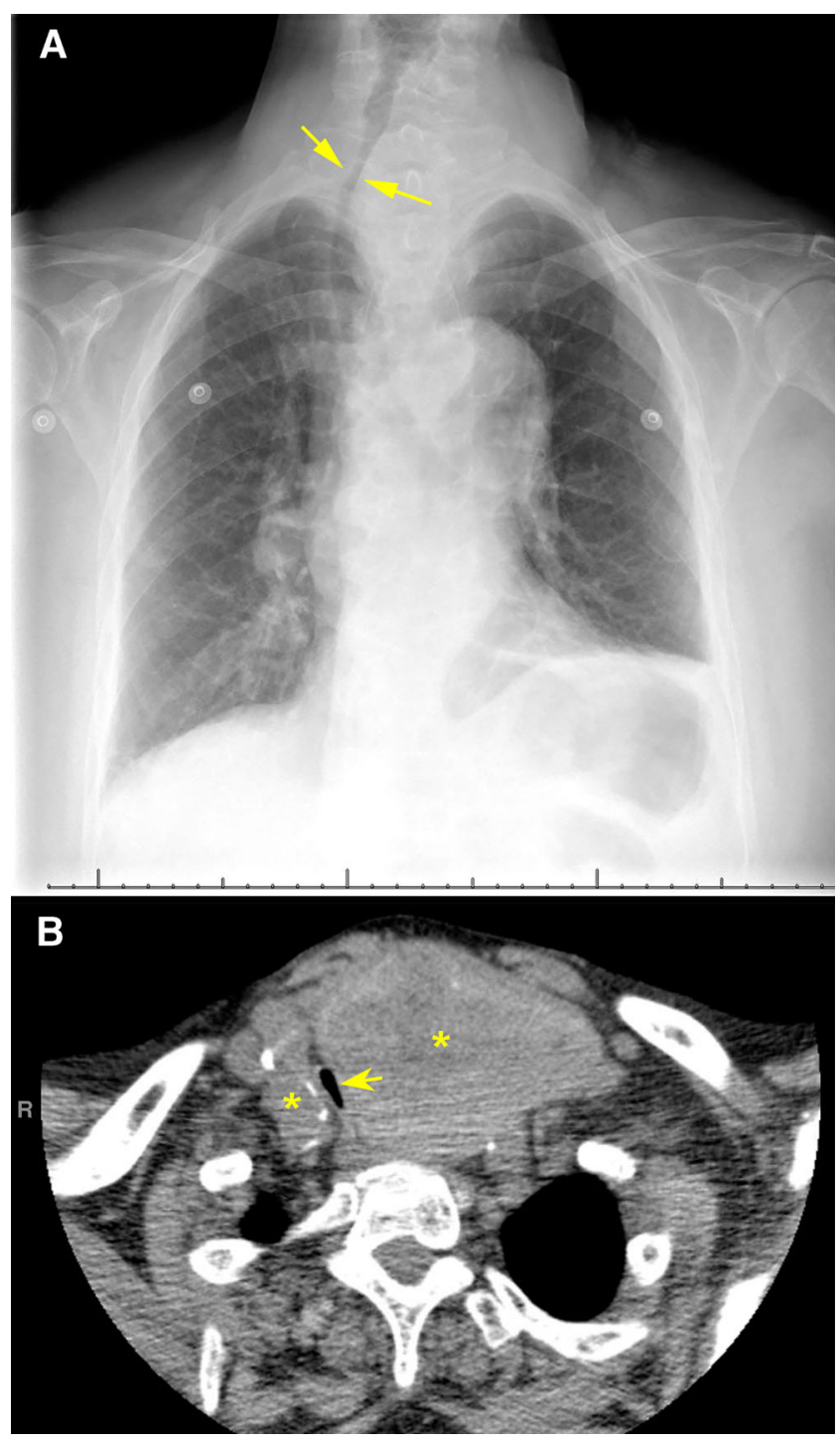

Figure 1 Prior to left hemithyroidectomy. a) Chest radiograph showing rightward deviation of the trachea with severe tracheal narrowing (arrows). b) Computed tomography of the chest demonstrating massive substernal thyroid (asterisks) and tracheal compression (arrow). 


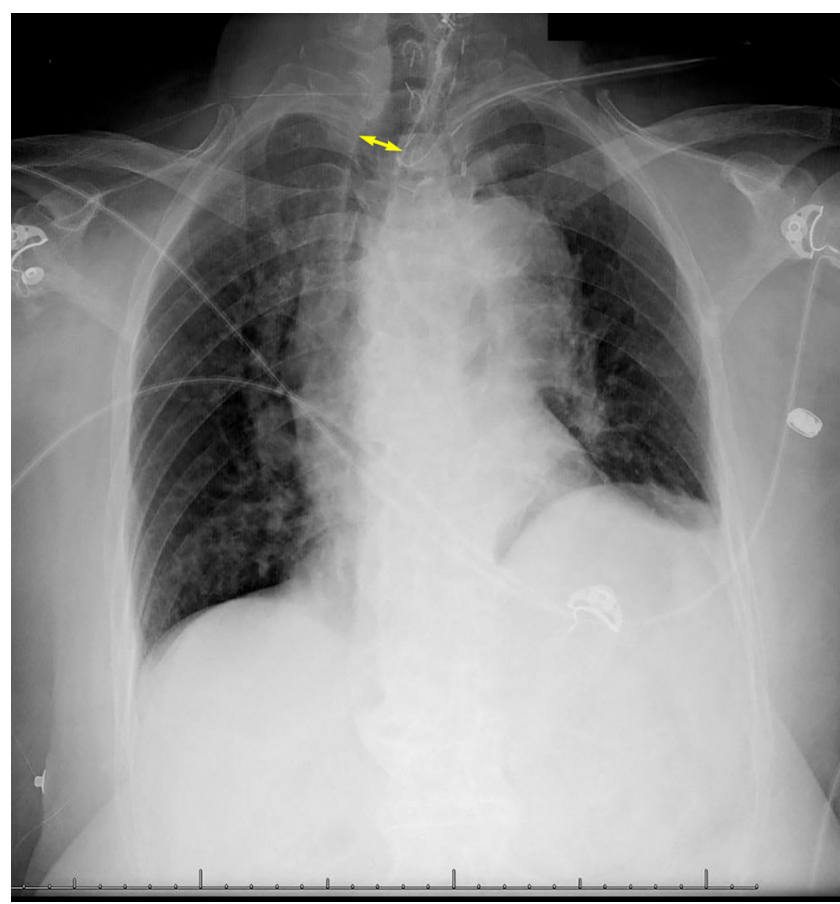

Figure 2 Chest radiograph after left hemithyroidectomy showing significant improvement in tracheal stenosis (arrows).
Corresponding Author: Paul B. Aronowitz, MD; Department of Internal MedicineUniversity of California, Davis, School of Medicine, Sacramento, CA, USA (e-mail: Paronowitz@ucdavis.edu).

\section{Compliance with Ethical Standards:}

Conflict of Interest: The authors declare that they have a conflict of interest.

Funding: None

\section{REFERENCES}

1. Miller MR, Pincock AC, Oates GD, Wilkinson R, Skene-Smith H. Upper airway obstruction due to goitre: detection, prevalence and results of surgical management. Q J Med. 1990;74(274):177-88.

2. Jauregui R, Lilker ES, Bayley A. Upper airway obstruction in euthyroid goiter. JAMA. 1977;238(20):2163-6.

3. Shaha AR, Burnett C, Alfonso A, Jaffe BM. Goiters and airway problems. Am J Surg. 1989;158(4):378-80.

4. Kadhim AL, Sheahan P, Timon C. Management of life-threatening airway obstruction caused by benign thyroid disease. J Laryngol Otol. 2006;120(12): 1038-41.

5. Chen AY, Bernet VJ, Carty SE, et al. American Thyroid Association statement on optimal surgical management of goiter. Thyroid Off $\mathrm{J}$ Am Thyroid Assoc. 2014;24(2):181-9.

6. Hashmi SM, Premachandra DJ, Bennett AMD, Parry W. Management of retrosternal goitres: results of early surgical intervention to prevent airway morbidity, and a review of the English literature. J Laryngol Otol. 2006;120(8):644-9. 